\title{
Stages of Behaviour Change Related to Physical Activity and the Associated Barriers among College-Going Adolescents in Puducherry- Cross Sectional Study
}

\author{
Angayarkanni A', Arivarasan Barathi ${ }^{2},{\text { Ramesh } R S^{3}}^{3}, \underline{\text { Subitha Lakshminarayanan }}^{4}$ \\ ${ }^{1}$ M.S.C., Community Health Nursing, JIPMER, Gorimedu, Puducherry. \\ ${ }^{2} J u n i o r$ Resident, ${ }^{4}$ Assistant Professor, Department of Preventive and Social Medicine, JIPMER, Gorimedu, Puducherry. \\ ${ }^{3}$ Assistant Professor, College of Nursing, JIPMER, Gorimedu, Puducherry.
}

DOI: https://doi.org/10.24321/2349.2880.202003

I $\quad \begin{array}{lllll}\mathbf{N} & \mathbf{F} & \mathbf{O}\end{array}$

\author{
Corresponding Author: \\ Arivarasan Barathi, Department of Preventive and \\ Social Medicine, JIPMER, Gorimedu, Puducherry. \\ E-mail Id: \\ ari_raj84@yahoo.com \\ Orcid Id: \\ https://orcid.org/0000-0002-3147-0799 \\ How to cite this article: \\ Angayarkanni A, Barathi A, Ramesh R, \\ Lakshminarayanan $\mathrm{S}$. Stages of Behaviour Change \\ Related to Physical Activity and the Associated \\ Barriers among College-Going Adolescents in \\ Puducherry- Cross Sectional Study. Ind J Youth \\ Adol Health 2020; 7(1): 15-22.
}

Date of Submission: 2020-06-21 Date of Acceptance: 2020-07-25

\section{$\begin{array}{llllllll}\mathbf{A} & \mathbf{B} & \mathbf{S} & \mathbf{T} & \mathbf{R} & \mathbf{A} & \mathbf{C} & \mathbf{T}\end{array}$}

Background: One in every ten deaths globally is reported by physical inactivity related risks. Adolescents constitute $18 \%$ of the total population, due to physical inactivity they are more at risk of noncommunicable diseases. This study aims to find the level, stages of behaviour changes, associated barriers related to physical activity among adolescents.

Methods: Quantitative, cross-sectional study was done at Tagore College based on Multi-stage cluster sampling. 920 adolescents in the age group of 18-19 years were included in the study. Global Physical Activity Questionnaire (GPAQ) and Trans theoretic models were used to assess the level of physical activity and stages of behaviour change related to physical activity. In addition, barriers to participating in physical activity were also elicited.

Result: About one-fifth of the subjects (20.4\%) were physically inactive. It was found that they are in pre-contemplation and contemplation stages (14.7\%) of behaviour change related to physical activity. Compared to females, males have a higher chance to do physical activity and was statistically significant $(p<0.001)$. The major barriers to physical activity were personal barriers like lack of time and having multiple tasks. Healthy practices in a family also found to have a significant association with increased physical activity. $(\mathrm{p}<0.001)$.

Conclusion: Many barriers were reported that prevent adolescents from taking up sufficient physical activity. Therefore, attempt should be taken to emphasize the importance of physical activity among family members, individuals, and the peer friends at the community level. Primordial prevention in the vital emergence of risk factors for NCDs like sufficient physical activity is vital for reducing burden of chronic diseases in our country.

Keywords: Adolescent Health, Physical Activity, Trans-Theoretical Model, Behaviour Change 


\section{Introduction}

Physiological movement and exercise produced by the involvement of skeletal muscles that need energy expenditure are called "physical activity". ${ }^{1}$ In 2016 globally, 32 percent of women and 23 percent of men aged more than 18 years are reported insufficient physical activity. ${ }^{2}$ Around 3.2 million people stated the mortality rate due to insufficient PA. Physical inactivity is the fourth leading risk factor for the cause of global mortality rate. ${ }^{1}$ PA prevents the risk of non-communicable disease like cancer in colon and breast, diabetes and ischemic heart disease. ${ }^{3}$ The failure to achieve the minimum level of activity increases the risk factors of NCD by 20 to $30 \%$ and reduces 3 to 5 years of individual lifespan. This does not only affect individuals, but it also increases the burden of society by productivity loss and increases medical care services. ${ }^{1}$ In 2013, global assembly for health targets for world voluntaries that reduce premature mortality up to $25 \%$ due to NCD and to achieve the reduction of physical inactivity to ten percentage by the year of $2025 .^{2}$

Total world population adolescents constitute $18 \%$, they are at more risk for physical inactivity in the near future. Basic prevention of risk factors for NCD like physical activity is essential to our country in the prevention of the increasing burden of NCD. ${ }^{5}$ Knowledge of the importance of sports and physical activities for adolescents should be fortified, reinforced, and make the possibility for doing PA within the environmental framework. The participation of adolescents in PA are interrupted by several barriers. ${ }^{6}$ To reduce the barriers among individuals, provide positive effects and eliminate negative possessions produced by physical inactivity.

Individuals in late adolescents are out of their schooling period and may engage in higher education in colleges and universities. The adolescent period has to easily inculcate a positive good attitude and behaviour taught to create a healthy society. These developmental phases are essential as they are entering becoming into adulthood. It may give an opportunity for getting risk factors like physical inactivity. All these vital issues that adolescents will face in the future is the development of burden of NCD. This study aims to find the level, stages of behaviour changes, associated barriers related to physical activity among college-going adolescents in Puducherry.

Adolescence show cast a critical developmental period of personal lifestyle choices and behaviour patterns, including the choice to be physically active. Physical inactivity and sedentary behaviour are major risk factors for the development of chronic diseases with resulting morbidity and mortality, as well as economic burden, and reduced occupational productivity. Worrying trends in physical inactivity behaviours necessitate urgent and concerned action. Healthcare professionals caring for late adolescents and young adults are suited to deliver powerful messages promoting physical activity and behaviour change. Every encounter represents an opportunity to question about physical activity, deliver advice, or provide the right pathways or opportunities. Key initial targets include getting everyone to decrease their sedentary behaviour and become more active, with even a little being more beneficial than none at all.

\section{Material and Methods}

A Quantitative, cross-sectional analytical study was conducted in Tagore govt Arts and Science College, Lawspet located about $6 \mathrm{kms}$ away from JIPMER hospital. This college for the study was chosen based on the Multi-stage cluster sampling technique. The study population consist of all late adolescents between the ages of 18 to 19 years registered in the selected college in Puducherry.

Standardized self-administered questionnaire was developed to capture details like socio-demographic data (age, gender and socio-economic status), medical and healthy lifestyle practices among the family members. Levels of physical inactivity were measured by WHO Questionnaire Global Physical Activity Questionnaire ${ }^{4}$ and behaviour stages related to PA were measured by Prochaska and Carlo Di Clemente Questionnaire Tran's theoretic models. ${ }^{7}$ In addition, barriers to participating in PA were also elicited. ${ }^{8}$

The sample size was estimated as 450 based on the prevalence of low physical activity to be $31 \%$ from literature. ${ }^{9}$ The sample size was calculated to be 836 with $95 \%$ confidence and $5 \%$ absolute precision, design effect as 2.5 using OpenEpi software. Assuming 10\% non-response or incomplete questionnaires, the final 920 sample size was calculated. All available students in the college who met the inclusion criteria those students were included in this study. 920 adolescents in the age group of 18-19 years were included in the study.

The study was approved by the (NRMC) Nursing Research Monitoring Committee, and the Institute ethics committee (JIPMER). The data collection was six weeks.

Eligible study participants were approached at their college during their free hours. Background and importance of the study were explained to the participants and written informed consent was obtained. The confidentiality of the details collected was assured to study participants. Selfadministered questionnaire in both Tamil and English was used to collect the data. Clarifications were given to the participants in case of doubts.

Epidata 3.1 used for data entry and fined the percentages, means, standard deviation, and confidence interval of various quantitative variables measured by SPSS package version 20 was used. The physical activity level was stated 
as proportions. Comparison between dissimilar groups like gender, socio-economic status, measured by the Chi-square test. The univariate analysis was done to show association of demographic variables and physical activity levels with confidence intervals of $95 \%$ and Odds ratio. The multivariable analysis was done to show an association of physical activity with sufficient and insufficient characteristics is expressed as an adjusted OR ratio.

\section{Result}

The mean age was 18.6 years were found the participants with SD of 0.47 .(Table 1) One-third of the participants spend more than 5 hours on media including mobile phones, television, and games. Lifestyle practices in family half of study participant family members did not following lifestyle practices.

Table I.Distribution of socio-demographic characteristics of study participants $(\mathbf{N}=\mathbf{9 2 0})$

\begin{tabular}{|c|c|c|c|}
\hline S. No. & Socio-demographic characteristics & Frequency $(n=920)$ & Percentage (\%) \\
\hline \multirow[t]{3}{*}{1.} & \multicolumn{3}{|c|}{ Age } \\
\hline & 18 & 305 & 33.2 \\
\hline & 19 & 615 & 66.8 \\
\hline \multirow[t]{3}{*}{2.} & \multicolumn{3}{|c|}{ Sex } \\
\hline & Male & 574 & 62.4 \\
\hline & Female & 346 & 37.6 \\
\hline \multirow[t]{4}{*}{3.} & \multicolumn{3}{|c|}{ Religion } \\
\hline & Hindu & 816 & 88.7 \\
\hline & Muslim & 22 & 2.4 \\
\hline & Christian & 82 & 8.9 \\
\hline \multirow[t]{3}{*}{4.} & \multicolumn{3}{|c|}{ Department in College ${ }^{\#}$} \\
\hline & Science departments & 368 & 40 \\
\hline & Arts departments & 552 & 60 \\
\hline \multirow[t]{3}{*}{5.} & \multicolumn{3}{|c|}{ Year of Study } \\
\hline & Second-year & 508 & 55.2 \\
\hline & Third-year & 412 & 44.8 \\
\hline \multirow[t]{6}{*}{6.} & \multicolumn{3}{|c|}{ Socio-Economic Classification $\$$} \\
\hline & Upper class (INR 7008 and above) & 76 & 8.3 \\
\hline & Upper middle Class (INR 3504-7007) & 143 & 15.5 \\
\hline & Middle Class (INR 2102-3503) & 231 & 25.1 \\
\hline & Lower middle Class (INR 1051-2101) & 316 & 34.3 \\
\hline & Lower Class (INR 1050 and below) & 154 & 16.7 \\
\hline \multirow[t]{3}{*}{7.} & \multicolumn{3}{|c|}{ Type f Family } \\
\hline & Joint family & 222 & 24.1 \\
\hline & Nuclear family & 698 & 75.9 \\
\hline \multirow[t]{5}{*}{8.} & \multicolumn{3}{|c|}{ Transport @ } \\
\hline & Public transport & 569 & 61.8 \\
\hline & Personal-bicycle & 41 & 4.5 \\
\hline & Personal-motorbike \& car & 220 & 23.9 \\
\hline & Pooling transport & 90 & 9.8 \\
\hline
\end{tabular}

\# Science departments include Mathematics, Physics, Botany, Zoology, Computer science, Psychology. Arts departments include Tamil, English, French, Commerce, and Sociology.

$\$$ BG Prasad socioeconomic classification. ${ }^{9}$

@ Public transport includes traveling in a bus, share auto, Auto. Pooling transport includes transport along with friends \& parents motorbike. 
Table 2.Distribution of Lifestyle characteristics at individual and family level among the study participants of adolescents $(\mathrm{N}=920)$

\begin{tabular}{|c|c|c|c|c|}
\hline S. No. & Category & Charac-teristics & Frequency $(n=920)$ & Percentage (\%) \\
\hline \multirow{3}{*}{1.} & \multirow{11}{*}{ Individual } & \multicolumn{3}{|c|}{ Recreation activities } \\
\hline & & Yes & 562 & 61.1 \\
\hline & & No & 358 & 38.9 \\
\hline \multirow{4}{*}{2.} & & \multicolumn{3}{|c|}{ Practice of yoga } \\
\hline & & Most days & 37 & 4.0 \\
\hline & & Sometimes & 309 & 33.6 \\
\hline & & Never & 574 & 62.4 \\
\hline \multirow{4}{*}{3.} & & \multicolumn{3}{|c|}{ Screen time ${ }^{@}$} \\
\hline & & $<3$ hours per day & 292 & 31.7 \\
\hline & & 3 to 5 hours per day & 315 & 34.2 \\
\hline & & $>5$ hours per day & 313 & 34.1 \\
\hline \multirow{6}{*}{4.} & \multirow{11}{*}{ Family } & \multicolumn{3}{|c|}{ Chronic disease in family } \\
\hline & & Hyper-tension & 165 & 17.9 \\
\hline & & Diabetes & 79 & 8.6 \\
\hline & & Heart disease & 30 & 3.3 \\
\hline & & Others & 58 & 6.3 \\
\hline & & None & 588 & 63.9 \\
\hline \multirow{5}{*}{5.} & & \multicolumn{3}{|c|}{ Lifestyle practices in family } \\
\hline & & Daily exercise & 214 & 23.3 \\
\hline & & Yoga \& Meditation & 70 & 7.6 \\
\hline & & Dietary restriction & 51 & 5.5 \\
\hline & & None & 585 & 63.6 \\
\hline
\end{tabular}

@ Screen time includes watching television, the use of mobile phones and games.

\$ Chronic disease in family others includes cancer, asthma, and thyroid disorder.

Table 3.Level of physical activity among the study participants $(\mathbf{N}=920)$

\begin{tabular}{|c|c|c|c|c|}
\hline Level of physical activity & $\begin{array}{c}\text { Male }(n=574) \\
n(\%)\end{array}$ & $\begin{array}{c}\text { Female } \\
(n=346) n(\%)\end{array}$ & $\begin{array}{c}\text { Overall n } \\
(\%)\end{array}$ & $\begin{array}{l}\text { Average time spent per week in } \\
\text { minutes, Median (IQR) }\end{array}$ \\
\hline $\begin{array}{l}\text { Sufficient Physical activity } \\
\text { (GPAQ>600MET-minutes) }\end{array}$ & $523(91.1)$ & $209(60.4)$ & $732(79.6)$ & \multirow{2}{*}{$\begin{array}{c}8760 \\
(3963-14160)\end{array}$} \\
\hline $\begin{array}{l}\text { Insufficient physical activity } \\
\text { (GPAQ<600MET-minutes) }\end{array}$ & $51(8.9)$ & $137(39.6)$ & $188(20.4)$ & \\
\hline
\end{tabular}

Table 4.Stages of behaviour change related to PA among the study participants of adolescents

\begin{tabular}{|c|c|c|c|}
\hline Stages of Behaviour Change & Male $(\mathbf{n}=\mathbf{5 7 4}) \mathbf{n}(\mathbf{\%})$ & Female $(\mathbf{n}=\mathbf{3 4 6}) \mathbf{n}(\%)$ & Overall $(\mathbf{n}=\mathbf{9 2 0}) \mathbf{n}(\%)$ \\
\hline Pre-contemplation \& Contemplation & $32(5.6)$ & $103(29.8)$ & $135(14.7)$ \\
\hline Preparation & $19(3.3)$ & $34(9.8)$ & $53(5.8)$ \\
\hline Action \& Maintenance & $523(91.1)$ & $209(60.4)$ & $732(79.5)$ \\
\hline
\end{tabular}


Table 5.Univariate analysis showing the association between PA and selected demographic variables among the study participants $(\mathbf{N}=920)$

\begin{tabular}{|c|c|c|c|c|c|}
\hline Variables & $\begin{array}{l}\text { Sufficient } \\
\text { PA-n=732 }\end{array}$ & $\begin{array}{c}\text { Insufficient } \\
\text { PA-n=188 }\end{array}$ & $\begin{array}{c}\text { Unadjusted } \\
\text { OR }\end{array}$ & $95 \% \mathrm{Cl}$ & p-value \\
\hline \multicolumn{6}{|l|}{ Age } \\
\hline 18 & $224(73.4)$ & $81(26.6)$ & Ref & \multirow{2}{*}{$1.23-2.38$} & \multirow{2}{*}{$0.01 *$} \\
\hline 19 & $508(82.6)$ & $107(17.4)$ & 1.71 & & \\
\hline \multicolumn{6}{|l|}{ Sex } \\
\hline Male & $523(91.1)$ & $51(8.9)$ & Ref & \multirow{2}{*}{$4.69-9.62$} & \multirow{2}{*}{$0.001 *$} \\
\hline Female & $209(60.4)$ & $137(39.6)$ & 0.14 & & \\
\hline \multicolumn{6}{|l|}{ Religion } \\
\hline Hindu & $651(88.9)$ & 165 (87.7) & Ref & \multirow{3}{*}{$\begin{array}{l}0.29-2.62 \\
0.69-2.04\end{array}$} & \multirow{3}{*}{0.7} \\
\hline Muslim & $18(2.4)$ & $4(2.12)$ & 0.87 & & \\
\hline Christian & $63(8.6)$ & $19(2.5)$ & 1.19 & & \\
\hline \multicolumn{6}{|l|}{ Department in college@ } \\
\hline Science departments & $298(40.7)$ & $70(37.2)$ & Ref & \multirow{2}{*}{$0.832-1.61$} & \multirow{2}{*}{0.3} \\
\hline Arts departments & $434(59.2)$ & $118(62.7)$ & 1.15 & & \\
\hline \multicolumn{6}{|l|}{ Type of family } \\
\hline Joint family & $179(24.4)$ & $43(22.8)$ & Ref & \multirow{2}{*}{$0.74-1.59$} & \multirow{2}{*}{0.6} \\
\hline Nuclear family & $553(75.5)$ & $145(77.1)$ & 1.09 & & \\
\hline \multicolumn{6}{|l|}{ Transport \$ } \\
\hline Active transport & $30(4.09)$ & $10(5.3)$ & Ref & \multirow{3}{*}{$\begin{array}{l}0.35-1.53 \\
0.42-2.37\end{array}$} & \multirow{3}{*}{0.3} \\
\hline Passive transport & $636(86.8)$ & $156(82.9)$ & 0.7 & & \\
\hline Pooling transport & $66(9.01)$ & $22(11.7)$ & 1.0 & & \\
\hline \multicolumn{6}{|c|}{ History of chronic disease in family \# } \\
\hline None & $225(30.7)$ & $49(26.1)$ & Ref & \multirow{3}{*}{$\begin{array}{l}0.52-1.08 \\
0.21-1.06\end{array}$} & \multirow{3}{*}{0.08} \\
\hline $\mathrm{DM} / \mathrm{HT} / \mathrm{HD}$ & $51(6.9)$ & $7(3.7)$ & 0.7 & & \\
\hline Others & $456(62.2)$ & $132(70.2)$ & 0.4 & & \\
\hline
\end{tabular}

${ }^{*} p<0.05$ is statistically significant

@ Science departments include Mathematics, Physics, Botany, Zoology, Computer science, Psychology. Arts departments include Tamil, English, French, Commerce, and Sociology.

$\$$ Public transport includes traveling in a bus, share auto, Auto. Pooling transport includes transport along with friends \& parents motorbike. \#Chronic disease in family others include cancer, asthma, and thyroid disorder.

Table 6.Distribution of Univariate analysis showing the association between PA and lifestyle characteristics of the participants $(N=920)$

\begin{tabular}{|c|c|c|c|c|c|}
\hline VARIABLES & $\begin{array}{c}\text { Sufficient PA } \\
\quad(n=732)\end{array}$ & $\begin{array}{l}\text { Insufficient } \\
\text { PA }(n=188)\end{array}$ & $\begin{array}{c}\text { Unadjusted } \\
\text { OR }\end{array}$ & $95 \% \mathrm{Cl}$ & p-value \\
\hline \multicolumn{6}{|c|}{ Recreation activities } \\
\hline Yes & $554(75.6)$ & $8(4.2)$ & Ref & \multirow{2}{*}{$0.007-0.03$} & \multirow{2}{*}{$0.001^{*}$} \\
\hline No & $178(24.3)$ & $180(95.7)$ & 0.14 & & \\
\hline \multicolumn{6}{|c|}{ Practice of yoga } \\
\hline Sometimes & $460(62.8)$ & $114(76.5)$ & Ref & \multirow{3}{*}{$\begin{array}{l}0.4-2.8 \\
0.4-2.4\end{array}$} & \multirow{3}{*}{0.7} \\
\hline Most days & $242(33.6)$ & $67(35.6)$ & 1.1 & & \\
\hline Never & $30(4.09)$ & $7(3.7)$ & 1.0 & & \\
\hline
\end{tabular}




\begin{tabular}{|c|c|c|c|c|c|}
\hline Screening time & & & & & \\
\hline$>$ 5hours per day & $245(33.4)$ & $70(37.2)$ & Ref & \multirow{3}{*}{$\begin{array}{l}0.6-1.3 \\
0.4-0.9\end{array}$} & \multirow{3}{*}{$0.05^{*}$} \\
\hline$<3$ hours per day & $263(35.9)$ & $50(26.5)$ & 0.9 & & \\
\hline 3 to 5 hours per day & $224(30.6)$ & $68(36.17)$ & 0.6 & & \\
\hline \multicolumn{6}{|c|}{ Healthy lifestyle practices in family\# } \\
\hline Yoga \& meditation & $194(26.5)$ & $19(12.1)$ & Ref & \multirow{3}{*}{$\begin{array}{l}1.4-5.3 \\
1.9-5.4\end{array}$} & \multirow{3}{*}{$0.001^{*}$} \\
\hline Dietary restriction & $94(12.8)$ & $26(13.8)$ & 2.8 & & \\
\hline None & $444(60.6)$ & $143(76)$ & 3.2 & & \\
\hline \multicolumn{6}{|c|}{ Chronic disease in a family } \\
\hline None & $456(62.2)$ & $132(70.2)$ & Ref & \multirow{3}{*}{$\begin{array}{l}0.5-1.0 \\
0.2-1.0\end{array}$} & \multirow{3}{*}{0.8} \\
\hline $\mathrm{DM} / \mathrm{HT} / \mathrm{HD}$ & $225(30.7)$ & $49(26)$ & 0.7 & & \\
\hline Others & $51(6.9)$ & $7(3.7)$ & 0.4 & & \\
\hline
\end{tabular}

${ }^{*} \mathrm{p}<0.05$ is statistically significant.

Table 7.Multivariable analysis showing the association of PA with sufficient and insufficient characteristics $(\mathbf{N}=920)$

\begin{tabular}{|c|c|c|c|c|c|}
\hline Category & Variables & $\begin{array}{c}\text { Sufficient PA } \\
\mathrm{n}=732(\%)\end{array}$ & $\begin{array}{c}\text { Insufficient PA } \\
\mathrm{n}=188(\%)\end{array}$ & Adjusted OR & p-value* \\
\hline & AGE & & & & \\
\hline & 18 & $224(73.4)$ & $81(26.6)$ & Ref & \multirow{2}{*}{$0.04 *$} \\
\hline \multirow{7}{*}{ Individual } & 19 & $508(82.6)$ & $107(17.4)$ & 0.6 & \\
\hline & SEX & & & & \\
\hline & Male & 523(91.1) & $51(8.9)$ & Ref & \multirow{2}{*}{$0.001 *$} \\
\hline & Female & $51(8.9)$ & 137(39.6) & 0.4 & \\
\hline & Recreation activities & & & & \\
\hline & Yes & $554(24.3)$ & $8(4.2)$ & Ref & \multirow{2}{*}{$0.001^{*}$} \\
\hline & No & $178(24.3)$ & 180(95.7) & 0.02 & \\
\hline & Healthy lifestyle practices in family\# & & & & \\
\hline & Yoga \& meditation & 194(26.5) & 19(10.1) & Ref & \\
\hline & Dietary restriction & $94(12.8)$ & $26(13.8)$ & 0.8 & \\
\hline \multirow{5}{*}{ Family } & None & $444(60.6)$ & $143(76.0)$ & 1.1 & 0.6 \\
\hline & Chronic disease in family $\$$ & & & & \\
\hline & None & $225(30.7)$ & $49(26)$ & Ref & \multirow{3}{*}{0.3} \\
\hline & $\mathrm{DM} / \mathrm{HT} / \mathrm{HD}$ & $51(6.9)$ & $7(3.7)$ & 0.8 & \\
\hline & Others & $456(62.2)$ & 132(70) & 0.5 & \\
\hline
\end{tabular}

${ }^{*} p<0.05$ is statistically significant.

\section{Measurement of Physical Activity}

From Table 2, we can see that one-third of participants their Sedentary behaviour includes usually time spend for reclining or sitting on a typical day like (sitting at a desk), spend more than 3 hours. Out of the 920 samples, $79.6 \%$ reported as having sufficient PA when compared to $32.4 \%$ with insufficient activity. Table 3 , shows that onethird of Female participants has reported insufficient PA compared to males its Similar to previous study ${ }^{11}$ the median value of PA level in this late adolescents is stated in 8760 MET- minutes. (IQR 3963-14160). Two-third of adolescents reported sufficient PA they are in action and maintenance stage. Compared to female, male reported high. Onefifth of participants reported the pre-contemplation and contemplation stage. They do not plan to change PA behaviour in the next 6 months (Table 4). 
Barriers of PA among the study participants related to insufficient PA. Personal barriers are I have many tasks, Lack of time and Psychological barriers like At home nobody performs PA, I do not feel motivated, and Environmental Barriers are adverse weather conditions, don't find nearby places like playgrounds. Two third of participants had personal barriers $53.2 \%$. One-fifth of participants reported environmental barriers $13.8 \%$. One-third of the participants reported psychological barriers 33\%.

Univariate analysis for selected variables among adolescents, age, and gender found that significant associations related to sufficient PA. Female gender has lesser odds of sufficient PA than males $(\mathrm{OR}=0.14,95 \% \mathrm{Cl}=0.10-0.21)$ and this was statistically significant. The presence of healthy practices in the family members had a stronger association with PA in the study population (OR=0.49, 95\% Cl 1.41-2.93) and that was statistically significant (Table 5 \& 6).

Multivariable analysis shows that variables are gender and recreation activity were independent determinants related to enough PA. Females reported lower odds of enough PA compared to males the same as family healthy lifestyle practices also have more chances of enough PA these variables are statistically significant $(p<0.001)$ after adjusting for confounding variables (Table 7).

\section{Discussion}

This study assessed the level, stages of behaviour, and barriers related to PA among late adolescents they revealed that one-fifth of the participants were having inadequate PA, i.e., $20.4 \%$. This study found that, compared to the female gender, males had sufficient PA. A study In Vellore, Tamil Nadu. The prevalence of physical inactivity was found to be $63.3 \%$ in urban and rural $40.6 \%$ respectively. ${ }^{13}$ These findings go in the opposite direction with the current study. While the study conducted in Selangor revealed $20.8 \%$ physical inactivity. ${ }^{14}$ These findings are similar to the current study. Research conducted in Nigeria reported $63 \%{ }^{15}$ and China found that around $77 \%{ }^{16}$ are physically inactive these findings support $\mathrm{WHO}$ reports.

Divyasree et al. ${ }^{17}$ conducted a study among adolescents in Puducherry revealed that one-third of late adolescents are insufficiently physically active in the adolescents was $31 \%$ respectively. Studies done by Kumar et al. ${ }^{18}$ revealed that $64 \%$ of the adolescents had an insufficient PA level, but our study supports the fact that late adolescents are doing sufficient physical activity.

Reasons behind that was most of the adolescents under low economic families are involving in part-time jobs (construction work, swiggy, labour man) and parents are having the occupation of agriculture and fishing so adolescents are also engaged in those activities to support by parents and peer friends also making them physically active.
The availability of playgrounds in college and knowledge in doing physical activity also encouraged students to be physically active. Most of the students come to college from rural they engaged travel by cycling or walking from places to college, these also engages adolescents to be active. This indicates an increased significant level of physical activity among adolescents.

This study finds that two-thirds of adolescents have reported in action and maintenance. Male (91.1) has a high PA when compared to females (60.4\%) where the action stage had already happened for over 6 months. Females were in precontemplation and contemplation stages comparatively high than males. On analysis of the Univariate female gender has a lesser odds ratio of sufficient PA than the male gender $(\mathrm{OR}=0.1,95 \% \mathrm{Cl} 4.6-9.6)$ and this was statistically significant. The major obstacles found in a female are like lack of time and engaged in a household activity. These all directly shows that physical activity level and stages of behaviour change related to PA are interrelated. The findings of the behaviour stage can improve the health behaviour of adolescents and also facilitate to plan up-gradation of health strategies designed to refine the level of PA in the community. Primordial and primary prevention of the vital emergence for NCD risk factors like being enough physical activity is important for constraining the flourishing burden of chronic diseases in our nation.

A vital strength of this study was the specificity of the age which was looked at the ages of 18 to 19 years. However, this is also a limitation of this study. This study does not generalized across all generations of adolescence. Upcoming future research could look at each period of adolescence to establish the key fact that support as well as prevent adolescents from sufficient PA. By practicing this, it may be feasible to avoid the decreasing rate of engaging in PA.

\section{Conclusion}

This study found that among the study participants onefifth of the adolescents are have not achieved enough physical activity almost $90 \%$ of males were in the action $\&$ maintenance stage compared to $60 \%$ in females. The one-third female was reported pre-contemplation \& contemplation stage. Two third of adolescents reported having personal barriers such as lack of time and having many tasks. Several barriers are preventing adolescents from taking up regular physical activity and exercise. Therefore effort should be taken to provide adequate knowledge and importance of being physically active among family members, friends, and all individuals in the community and institution level to create a basic foundation for healthy lifestylepractices for the future. Primordial and primary prevention of the vital emergence forNCD risk factors like being enough physical activity is important for constraining theflourishing burden of chronic diseases in our nation. 


\section{Conflicts of Interest: None \\ References}

1. World Health Organization. Physical activity. 2018. Available from http://www.who.int/topics/physical activity/en/. (Accessed on December 16 ${ }^{\text {th }}$ 2018).

2. World Health Organization. Fact sheet. 2018. Available from http://www.who.int/mediacentre/factsheets/ fs385/en/. (Accessed on December 16 $6^{\mathrm{th}}$ 2018).

3. World health organization. Prevalence of insufficient physical activity. 2016 Available from http://www. who.int/gho/ncd/risk-factors/physical-activity-text/ en/.(Accessed December 16 $6^{\text {th }}$ 2018).

4. Prochaska O, Clements D. Transtheoretical model beginning in 1977. Available from https: //en.wikipedia. org/wiki/Transtheoretical_model.(Accessed November 9, 2018).

5. Teixeira JP, Carraca E, Markland D, Silva MN, Ryan RM. Exercise, physical activity, and self -determination theory: A systematic review. Int J Behav Nutr Phys Act 2012; 9: 78.

6. WHO Regional Office for the Eastern Mediterranean.2018. Accessed from http://www.who. int/about/regions/emro/en/. (Accessed on December $17^{\text {th, }}$ 2018).

7. World Health Organization. Global Physical Activity Questionnaire. Available from http://www.who.int/ chp/steps/GPAQ_EN.pdf. (Accessed November $9^{\text {th }}$, 2018).

8. Maccarini P, Tatiane M, Rafaella R, Luis F, Cati R, Daniela L. perceived barriers to physical activity practice in high school students. Rev Bras Cineantropom 2016: 18: 5-6.

9. Divyasree P, Kumar GD, Subitha L, Ramesh RS. Level, motivation, and barriers to participating in physical activity among late adolescents in Puducherry. Int $J$ Adolesc Med health 2018 Oct 31.

10. Prasad BG socio-economic classification. Indian journal of community health /vol 31/issue no 01/jan-May 2019. (Accessed on November 2019).

11. Ministry of health and welfare Government of India. Integrated Disease Surveillance Project. Non-communicable diseases risk factor survey. 2009 available from http://www.icmr.nic.in/final/ IDSPNCD\%20Reports/Phase1\%20States\%20of\%20 India.pdf. (Accessed on January 20th).

12. Kumar D, Parashar A, Thakur A. How active is Our Young Generation: An Assessment of Physical Activities among Youth in a City of Northern India. Ind J Youth Adol Health 2016; 3: 21-25.

13. Corol S, Anu O, GK M, Vinod J, Kurian G. Level of physical inactivity in rural and urban Tamil Nadu, India; Across sectional study. Clinical and preventive cardiology 2019; 8(1): 13-17.
14. Aniza I, Fairuz MR. Factors influencing physical activity level among secondary school adolescents in Petaling District, Selangor. Med J Malasia 2009; 64: 228-232.

15. Dwyer JJM, Allison KR, Goldenberg ER, Fein AJ, Yoshiba KK, Boutilier MA. Adolescent Girls" Perceived Barriers to Participation in Physical Activity. Adolescence 2006; 41: 161.

16. Wu XY, Han LH, Zhang JH, Luo S, Hu JW, Sun K. The influence of physical activity, sedentary behavior on health-related quality of life among the general population of children and adolescents: A systematic review. PloS one 2017; 12(11): e-0187668.

17. Divyasree P, Kumar GD, Subitha L, Ramesh RS. Level, motivation, and barriers to participating in physical activity among late adolescents in Puducherry. Int $J$ Adolesc Med health 2018 Oct 31.

18. Kumar D, Parashar A, Thakur A. How active is Our Young Generation: AnAssessment of Physical Activities among Youth in a City of Northern India. Ind J Youth Adol Health 2016; 3: 21-25. 